\title{
Temas geradores e trabalho pedagógico no Centro Estadual Integrado de Educação Rural de Águia Branca, Espírito Santo
}

Rainei Rodrigues Jadejiski ${ }^{1}$, Ramofly Bicalho ${ }^{2}$

\begin{abstract}
Resumo
O presente trabalho é fruto de uma dissertação de mestrado sobre as possibilidades de contextualização da Educação Ambiental no Centro Estadual Integrado de Educação Rural de Águia Branca (CEIER-AB). Tem, como objetivo central, relatar os modos de organização pedagógica dessa instituição escolar, apresentando as possíveis interfaces entre os temas geradores, o trabalho pedagógico e a realidade de vida dos estudantes. Em relação às questões metodológicas, utilizamos a pesquisa bibliográfica, documentos da escola-campo, observações, vivências, conversas e questionários aplicados aos estudantes e professores da $3^{\text {a }}$ Série do Ensino Médio Integrado ao Curso Técnico em Agropecuária. Investigamos a organização do trabalho com os temas geradores, pautada, predominantemente, na obra Pedagogia do Oprimido, de Paulo Freire (2014). No trabalho com esses temas, identificamos que as questões do campo ambiental e social foram contempladas neste estudo. Compreendemos que tais questões ressoam no discurso e na tomada de consciência dos estudantes, demonstrando em suas falas, um enorme senso crítico. Constatamos, ainda, que as interfaces entre os temas geradores e o trabalho pedagógico possibilitaram uma estreita aproximação entre os saberes científico e popular.
\end{abstract}

\section{Palavras-chave}

Temas geradores. Trabalho pedagógico. Escola do campo. Educação ambiental.

\footnotetext{
${ }^{1}$ Mestre em Educação pela Universidade Federal Rural do Rio de Janeiro, Brasil; professor da rede estadual de educação do Espírito Santo, Brasil; coordenador pedagógico do Centro Estadual Integrado de Educação Rural de Águia Branca (CEIER-AB). E-mail: raineirj@ hotmail.com.

${ }^{2}$ Doutor em Educação pela Universidade Estadual de Campinas, São Paulo, Brasil, com estágio pós-doutoral na Universidade Federal Fluminense, Rio de Janeiro, Brasil; professor associado II do Departamento de Educação do Campo, Movimentos Sociais e Diversidade do Instituto de Educação, Universidade Federal Rural do Rio de Janeiro, Brasil. E-mail: ramofly@gmail.com.
} 
Generating themes and pedagogical work at the Centro Estadual Integrado de Educação Rural de Águia Branca, State of Espírito Santo, Brazil

Rainei Rodrigues Jadejiski ${ }^{3}$, Ramofly Bicalho ${ }^{4}$

\begin{abstract}
The present work is the result of the Master Thesis on the possibilities of contextualization of Environmental Education at Centro Estadual Integrado de Educação Rural de Águia Branca (CEIER-AB). Its main objective is to understand the possible interfaces between the generator themes, the pedagogical work and the students' reality of life. Regarding the methodological issues we used predominantly the bibliographic research, school documents, observations, experiences and questionnaires applied to students and teachers of the 3rd grade of the High School Integrated to the Technical Course in Farming. We investigated the organization of the work with Generating Themes, based predominantly on Paulo Freire's Pedagogy of the oppressed (2014). Working with the generating themes, we identified that the environmental and social issues were contemplated in this study. We understand that such questions resonate with students' discourse and awareness, demonstrating in their speech an enormous critical sense. We also found that the interface between generator themes and pedagogical work allowed a close approximation between scientific and popular knowledge.
\end{abstract}

\title{
Keywords
}

Generator themes. Pedagogical work. Field School. Environmental education.

\footnotetext{
${ }^{3}$ Master in Education, Federal Rural University of Rio de Janeiro, Brazil; professor at the state education network in Espírito Santo, Brazil; pedagogical coordinator of the Integrated State Center for Rural Education of Águia Branca (CEIER-AB). E-mail: raineirj@ hotmail.com.

${ }^{4} \mathrm{PhD}$ in Education, State University of Campinas, State of São Paulo, Brazil, with a post-doctoral internship at the Universidade Federal Fluminense, State of Rio de Janeiro, Brazil; associate professor II at the Department of Rural Education, Social Movements and Diversity at the Institute of Education, Federal Rural University of Rio de Janeiro, Brazil. E-mail: ramofly@gmail.com.
} 


\section{Introdução e procedimentos metodológicos}

O presente trabalho comunica resultados de uma pesquisa de mestrado realizada no Centro Estadual Integrado de Educação Rural de Águia Branca (CEIER-AB), no estado do Espírito Santo, durante o segundo semestre do ano letivo de 2018. O CEIER-AB é uma instituição escolar localizada no interior do município de Águia Branca e mantida pela rede estadual de ensino do Espírito Santo. Trata-se de uma escola do campo que oferta os anos finais do ensino fundamental e o ensino médio integrado ao Curso Técnico em Agropecuária.

Considerando a complexidade que tece o processo de ensino-aprendizagem, o CEIER$\mathrm{AB}$ propõe um trabalho com temas geradores (TG). Esses temas são temáticas previamente estabelecidas, resultado de seminários, palestras e envolvimento das comunidades locais. Diante da perspectiva agroecológica adotada pelo CEIER-AB, os temas contemplam a educação ambiental de uma forma interdisciplinar. Eles se aproximam da conceituação de temas geradores proposta por Freire (2014). Esse autor reforça a importância de as escolas se reinventarem a partir de suas realidades, como veremos adiante.

O trabalho com os TG foi estabelecido em diálogo com as vivências e experiências sistematizadas na escola, a partir de uma pesquisa participativa junto às comunidades onde os estudantes residem. Os TG são ferramentas essenciais para estreitar possíveis vínculos entre as diferentes comunidades no entorno da escola, as histórias de vida, o senso comum e o conhecimento científico. Eles se traduzem em um importante mecanismo de problematização da realidade. "Uma realidade que mesmo marcada por opressões e injustiças, continua reivindicando alterações sociais, profundas e imediatas, no campo brasileiro" (BICALHO; SILVA, 2016, p. 137).

No presente artigo, temos a participação intensa de estudantes e professores como sujeitos da pesquisa. Ela foi autorizada pela direção do CEIER-AB e, por meio do processo de número 23083.024560/2018-10, aprovada pelo Comitê de Ética da Universidade Federal Rural do Rio de Janeiro (UFRRJ). À luz dos princípios éticos, a UFRRJ realizou a avaliação do que pretendíamos pesquisar, tendo como preocupação os direitos e a integridade dos sujeitos pesquisados. Com a aprovação da pesquisa pela gestão da escola e pelo Comitê de Ética, iniciamos os contatos com estudantes e professores, dando ciência dos objetivos da pesquisa. Importante informar que obtivemos o consentimento livre e esclarecido de todos os sujeitos que participaram desta pesquisa. 
A realização do trabalho no CEIER-AB aconteceu no segundo semestre letivo do ano de 2018. Nesse contexto, a pesquisa privilegiou a observação da rotina escolar e o acompanhamento dos planejamentos individuais, coletivos e por área de conhecimento. Realizamos conversas com estudantes, professores e demais profissionais da escola. Em relação aos aspectos metodológicos, trabalhamos com aplicação de questionários com perguntas abertas e fechadas para 13 professores e 17 estudantes da $3^{\mathrm{a}}$ série do Ensino Médio Integrado ao Curso Técnico em Agropecuária. Escolhemos a referida turma para compor nossa pesquisa pelo fato de os estudantes já terem uma vivência maior com os TG. Importante sinalizar que professores e estudantes participaram, voluntariamente, da pesquisa, respondendo aos questionários.

$\mathrm{Na}$ análise dos dados, utilizamos a metodologia dialética por se tratar de uma abordagem investigativa que contribui com as reflexões acerca das contradições existentes no fenômeno pesquisado e no contexto social. Gil (2008, p. 14) esclarece que "a dialética fornece as bases para uma interpretação dinâmica e totalizante da realidade, uma vez que estabelece que os fatos sociais não podem ser entendidos quando considerados isoladamente, abstraídos de suas influências políticas, econômicas, culturais", ou seja, é necessária uma análise ampla da realidade pesquisada estabelecendo relações entre as situações analisadas e os diversos elementos presentes na sociedade.

\section{Os temas geradores: fundamentação teórica em Paulo Freire}

Para fundamentar teoricamente nossas reflexões acerca dos TG, apoiaremo-nos basilarmente nas argumentações propostas por Paulo Freire, em seu livro Pedagogia do Oprimido (2014). Nessa obra, o autor discute de forma clara e concisa diversos pressupostos que nos ajudam a entender os TG, partindo de pressupostos teórico-metodológicos que dialogam com a realidade dos estudantes. Ao abordar as relações homem-mundo, a partir dos TG, Freire esclarece que o conteúdo programático da educação dialógica retrata os anseios do povo e as situações de opressão, em diálogo com a compreensão crítica da realidade. $\mathrm{Na}$ busca por uma educação libertadora, é imprescindível que o educador conheça o educando e as práticas socioeconômicas que se desenrolam na comunidade. Freire (2014, p. 121) salienta que é "na realidade mediatizadora, na consciência que dela tenhamos, educadores e povo, que iremos buscar o conteúdo programático da educação". Nessa mesma linha de raciocínio, o 
autor busca compreender o pensamento-linguagem dos sujeitos, sua visão de mundo, os níveis de percepção de uma dada realidade e as possíveis articulações com os TG.

Freire (2014) compreende que os TG não são criações arbitrárias tampouco se constituem em hipóteses de trabalho que necessitam de comprovações. O autor enfatiza que se o TG fosse uma hipótese a ser comprovada, sua investigação, primeiramente, não seria em torno dele, mas de sua existência ou não. Sendo assim, Freire afirma que, antes de tentar apreender o TG em sua totalidade, é necessário primeiro constatar sua objetividade e, logo em seguida, captá-lo. Nessa lógica, diz que "a constatação do tema gerador, como uma concretização, é algo que chegamos através, não só da própria experiência existencial, mas também de uma reflexão crítica sobre as relações homens-mundo e homens-homens, implícitas nas primeiras" (FREIRE, 2014, p. 122).

$\mathrm{O}$ autor realça a existência histórica dos seres humanos. Além de viver, existem e têm consciência da sua existência e relações que estabelecem no e com o mundo. Com essa consciência, os homens e mulheres estabelecem uma relação dialética entre suas restrições e autonomia. Quando homens e mulheres enfrentam sua realidade, percebendo-a de forma crítica, têm condições de desenvolver a esperança, a confiança e romper com as barreiras que impedem a superação das situações-limites. Tais barreiras são impostas aos indivíduos pela sociedade, determinando um limite simbólico que pode impedir os sujeitos, individuais e coletivos, de romper com a visão fatalista do mundo. Essas situações-limites mantêm uma ordem social vigente, diretamente vinculada aos interesses da elite dominante, numa estreita relação entre opressores e oprimidos. Por outro lado, através da ação transformadora da realidade objetiva, é possível que os sujeitos rompam com os limites impostos, superando as contradições da sociedade (FREIRE, 2014).

Nesse contexto, Freire (2014) ressalta que a multiplicidade dos TG pode contribuir com tomadas de posição contraditórias, dado que uns sujeitos realizam tarefas de manutenção das estruturas e outros lutam para modificá-las. Nessa lógica freiriana, a ação libertadora mantém relações de correspondência com esses temas. Eles partem do universo mais amplo ao mais específico, numa perspectiva de apropriação da realidade e do mundo e, se realizados por meio de uma metodologia conscientizadora, inserem ou começam a inserir os homens numa forma crítica de pensarem seu mundo.

Ainda nesse debate, Freire (2014, p. 136) afirma ser "importante reenfatizar que o tema gerador não se encontra nos homens isolados da realidade, nem tampouco na realidade 
separada dos homens. Só pode ser compreendido nas relações homem-mundo”. Por fim, esclarece que:

Os temas, em verdade, existem nos homens, em suas relações com o mundo, referidos a fatos concretos. Um mesmo fato objetivo pode provocar, numa subunidade epocal, um conjunto de temas geradores, e, noutra, não os mesmos, necessariamente. Há, pois, uma relação entre o fato objetivo, a percepção que dele tenha os homens e os temas geradores. É através dos homens que se expressa a temática significativa e, o expressar-se, num certo momento, pode já não ser, exatamente, o que antes era, desde que haja mudado sua percepção dos dados objetivos aos quais os temas se acham referidos. (FREIRE, 2014, p. 137).

Seguindo nessa lógica, compreendemos, a partir das teorizações de Freire (2014), que o ponto de partida do processo de ensino-aprendizagem é a investigação dos TG. Por meio do diálogo característico da educação libertadora, parte-se de situações reais e concretas e se compreende as suas nuances e complexidades, buscando explicações nos diferentes níveis de compreensão da realidade. Nesse sentido, é fundamental a participação dos educadores, problematizando todo processo com os estudantes, estimulando-os a buscarem alternativas, pois os TG necessitam de respostas teóricas e ação. Rompe-se com visões fatalistas da realidade. A leitura e releitura da realidade vivida é essencial, pois teoria e prática não podem ser concebidas de forma isolada.

Segundo Freire (2014), a busca pelo Tema Gerador é uma prática coletiva. Ela deve aliar os saberes historicamente construídos aos saberes da educação popular e dos sujeitos, individuais e coletivos, envolvidos no processo de produção do conhecimento. A investigação temática não pode ser reduzida a um ato mecânico. Ela exige que os sujeitos interpenetrem nos problemas, compreendendo gradativamente a totalidade dos fatos. Nesse sentido, não é possível que educadores e educadoras apliquem um determinado programa educativo aos seus educandos, sem diálogos, pois a investigação temática não se dá fora do pensar dos homens sobre a realidade: "educação e investigação temática, na concepção problematizadora da educação, se tornam momentos de um mesmo processo" (FREIRE, 2014, p. 142).

A tarefa do educador na lógica freiriana passa pela devolução dos TG como problemas e não como respostas aos sujeitos de quem recebeu. Esses temas são centrais na realidade do educando. Permeiam todo processo educacional, pois são apreendidos a partir de investigação prévia da realidade dos estudantes. Freire (2014) alerta para necessidade de os conteúdos serem apropriados para cada localidade, pois cada comunidade apresenta uma realidade bem 
particular. Portanto, na concepção de Freire, as situações limites também são diferentes em cada lugar.

\begin{abstract}
Numa visão libertadora, não mais "bancária" da educação, o conteúdo programático já não involucra finalidades a serem impostas ao povo, mas, pelo contrário, porque parte e nasce dele, em diálogo com os educadores, reflete seus anseios e esperanças. Daí a investigação temática como ponto de partida do processo educativo, como ponto de partida de sua dialogicidade. (FREIRE, 2014, p. 143).
\end{abstract}

Em síntese, Freire (2014) enumera três momentos distintos para concretização da investigação temática. Na busca por uma compreensão do processo de ensino-aprendizagem, o primeiro momento passa pela delimitação da área de trabalho, o segundo pela apreensão de um conjunto de contradições e o terceiro abrange os diálogos decodificadores. É importante, ao considerar tais aspectos, reafirmar que o conteúdo programático não pode ser imposto aos estudantes numa relação vertical. Ele deve ser a devolução organizada de aspectos próprios da realidade em que os educandos estão inseridos.

Nessa compreensão, também se faz necessário ressaltar que o conteúdo programático, ao partir da realidade, não deve se limitar a ela, mas ultrapassá-la num movimento constante de ação, reflexão e práxis educativa. No CEIER-AB, compreendemos que o trabalho pedagógico com os TG toma a realidade como ponto de partida para apreensão dos saberes historicamente construídos pelos sujeitos, individuais e coletivos, do campo e que o modo como essa instituição escolar faz uso dos TG tem proximidade com a proposta de Paulo Freire.

O modo com o CEIER-AB desenvolve seu trabalho pedagógico com os TG se aproxima do modo como outras instituições trabalham com esses temas em diversas localidades. Ao abordar outro contexto de trabalho escolar com os TG, Bicalho e Oliveira (2017, p. 5) apontam que eles têm, “como objetivo principal, definir situações de interesses e motivações de educadores e educandos, numa determinada região. Pode[m] interferir na transformação dos sujeitos, individuais e coletivos, considerando as diferentes realidades".

Nessa lógica, Caliari (2013, p. 417) esclarece, no contexto de sua pesquisa, que

os temas são considerados geradores uma vez que envolvem todas as disciplinas do currículo; constam os objetivos de cada tema a ser trabalhado e as atividades a serem desenvolvidas nas sessões, no meio familiar e no meio escolar, próprias de cada tema de estudo; possibilitam adaptação do currículo à realidade dos educandos, relacionando os assuntos a serem estudados nos períodos letivos, fundamentando o Plano de Estudo e de aula.

Rev. Ed. Popular, Uberlândia, v. 19, n. 2, p. 240-257, maio-ago. 2020 
Em contexto similar ao da nossa escola-campo, os estudos pautados nos TG, foram apontados por Silva (2018) como importantes, pois possibilitam que os jovens participem de diferentes práticas sociais de uso da linguagem, como entrevistar, tomar notas, elaborar relatos das experiências vivenciadas, além de permitir que eles visualizem e compreendam o significado político-social dos conteúdos para a formação humana integral.

\section{A pedagogia do CEIER-AB: o trabalho pedagógico a partir dos temas geradores}

O conjunto de documentos arquivados no acervo do CEIER-AB nos possibilita afirmar que a escola intensificou o trabalho pedagógico com os TG, a partir do ano de 1991. O Centro desenvolveu uma proposta interdisciplinar, voltada para educação ambiental, com foco na agroecologia. Tal proposta, adotada pelos três Centros Estaduais Integrados de Educação Rural no Espírito Santo - Águia Branca, Boa Esperança e Vila Pavão - aproximou a formação geral e específica no processo de ensino-aprendizagem com os estudantes.

A escolha dos TG foi resultado de seminários, palestras e participação das comunidades onde residem os estudantes dos três Centros. Muito embora os temas tenham sido selecionados ${ }^{5}$ inicialmente para trabalhar nos Centros, cada CEIER realizou articulações, de acordo com sua realidade, considerando o público que atende. Os temas ligados à educação ambiental surgiram como mecanismos de promoção de ações e compreensão do acelerado panorama de degradação do meio ambiente. Essa realidade pode ser percebida, sobretudo, nas proximidades do CEIER-AB, onde a monocultura e a pecuária intensificam o processo de desolação ambiental.

Cabe realçar que os TG não são fixos e podem variar de acordo com as necessidades que despontam no contexto social, político, econômico e cultural da região em que a escola está inserida, além do público que ela atende. Nessa vertente, o trabalho pedagógico com os TG no CEIER-AB possibilita articulações entre os saberes historicamente construídos, previstos no currículo oficial, a realidade socioeconômica das comunidades, bem como os interesses específicos que os estudantes manifestam a partir de suas vivências e por meio das pesquisas sobre a realidade. Importante sinalizar que o trabalho desenvolvido pela escola, de forma dinâmica e participativa, permite que os diferentes ritmos de aprendizagens e os interesses dos estudantes sejam considerados e respeitados.

\footnotetext{
5 Segundo Freire (2014), os temas geradores explicam as contradições de uma dada realidade por um determinado tempo.
} 
Nessa direção, para desvelarmos uma realidade opressora, é necessário partir de situações-limite comunitárias. Tais situações causam opressão na sociedade. Elas não devem ser encaradas como problemas individuais, e sim sociais e comunitários (FREIRE, 2014). Nesse mesmo propósito, os princípios da educação do campo dialogam com as necessidades coletivas e de lutas por terra e políticas públicas. Rompe-se com o individualismo e a armadilha da meritocracia, defendido pelo sistema capitalista, no qual os sujeitos, por esforço individual, conseguem isoladamente algumas pequenas conquistas (BICALHO, 2017).

Os TG trabalhados no CEIER-AB são abrangentes e divididos em subtemas, de acordo com a série e o trimestre. Eles são motivadores para o desenvolvimento do conteúdo programático de cada disciplina. Os professores trabalham os conceitos relacionados ao tema do trimestre, flexibilizando o currículo oficial da rede estadual e estabelecendo pontes entre o conteúdo programático e as questões que emergem dos TG, considerando as especificidades das disciplinas.

Percebemos que tanto Paulo Freire quanto os referenciais teóricos específicos das políticas públicas de Educação do Campo questionam o currículo oficial. Tais teóricos defendem uma organização curricular em que os sujeitos, individuais e coletivos, façam-se presentes e consigam romper com a lógica urbanocêntrica. A divisão dos temas que nortearam o fazer pedagógico da Unidade Escolar em 2018 pode ser observada na sistematização expressa no quadro que segue:

Quadro 1 - Temas Geradores trabalhados no CEIER-AB

\begin{tabular}{|c|c|c|c|c|}
\hline Modalidade & Série & $\begin{array}{ll}\text { Subtemas } & \text { do } \\
\text { Trimestre } & 1^{\circ} \\
\text { (Tema } & \text { Gerador: } \\
\text { Água) } & \end{array}$ & $\begin{array}{l}\text { Subtemas do } 2^{\mathbf{o}} \\
\text { Trimestre } \\
\text { (Tema Gerador: Solo } \\
\text { e Questão Agrária) }\end{array}$ & $\begin{array}{l}\text { Subtemas do } \mathbf{3}^{\circ} \\
\text { Trimestre } \\
\text { (Tema Gerador: } \\
\text { Agrofloresta) }\end{array}$ \\
\hline \multirow{4}{*}{$\begin{array}{c}\text { Ensino } \\
\text { Fundamental }\end{array}$} & $6^{\circ}$ ano & $\begin{array}{l}\text { O ciclo da água e uso } \\
\text { doméstico }\end{array}$ & $\begin{array}{l}\text { Formação } \\
\text { composição do solo/ } \\
\text { Horta caseira }\end{array}$ & $\begin{array}{l}\text { Agrofloresta e seres } \\
\text { vivos }\end{array}$ \\
\hline & $7^{\circ}$ ano & $\begin{array}{l}\text { Captação e } \\
\text { reutilização da água }\end{array}$ & $\begin{array}{l}\text { Degradação } \\
\text { recuperação do solo/ } \\
\text { Família }\end{array}$ & $\begin{array}{l}\text { Biodiversidade } \\
\text { floresta }\end{array}$ \\
\hline & $8^{\circ}$ ano & $\begin{array}{lr}\text { Utilização } & \mathrm{e} \\
\text { preservação } & \text { dos } \\
\text { recursos hídricos } & \end{array}$ & $\begin{array}{l}\text { Práticas e manejo do } \\
\text { solo/ } \\
\text { Conservação do solo }\end{array}$ & $\begin{array}{l}\text { Monocultura } \\
\text { diversidade }\end{array}$ \\
\hline & $9^{\circ}$ ano & $\begin{array}{l}\text { Utilização } \quad \text { dos } \\
\text { recursos hídricos no } \\
\text { município }\end{array}$ & $\begin{array}{l}\text { Aptidão e subprodutos } \\
\text { do solo }\end{array}$ & $\begin{array}{l}\text { A importância da } \\
\text { agrofloresta para a } \\
\text { manutenção do solo / } \\
\text { Revolução Verde }\end{array}$ \\
\hline
\end{tabular}




\begin{tabular}{|c|c|c|c|c|}
\hline \multirow{3}{*}{$\begin{array}{l}\text { Ensino } \\
\text { Médio }\end{array}$} & $1^{\circ}$ ano & $\begin{array}{lr}\text { Preservação } & \mathrm{e} \\
\text { recuperação } & \text { dos } \\
\text { recursos hídricos } & \end{array}$ & $\begin{array}{l}\text { Função social } \\
\text { valorização da terra }\end{array}$ & Permacultura \\
\hline & $2^{\circ}$ ano & $\begin{array}{ll}\text { Contaminação } & \text { dos } \\
\text { recursos hídricos } & \end{array}$ & $\begin{array}{l}\text { Práticas alternativas de } \\
\text { manejo do solo }\end{array}$ & $\begin{array}{l}\text { Formação e manejo de } \\
\text { agrofloresta }\end{array}$ \\
\hline & $3^{\circ}$ ano & $\begin{array}{l}\text { Recuperação } \\
\text { nascentes e controle } \\
\text { de erosão com o } \\
\text { aproveitamento da } \\
\text { água }\end{array}$ & $\begin{array}{l}\text { Movimentos sociais e } \\
\text { questão agrária }\end{array}$ & Código Florestal \\
\hline
\end{tabular}

Fonte: Plano de Desenvolvimento Institucional (PDI) da escola (2017).

Ao considerar a organização exposta no quadro acima, é importante ressaltar que ela pode sofrer alterações de acordo com as demandas que surgem no cotidiano escolar. Essa estrutura dinâmica pode viabilizar adequações e atender as possíveis realidades da escola. Realidades que geralmente estão em constante movimento, pois o currículo no CEIER-AB é marcado pelo dinamismo e o processo de ensino-aprendizagem dialoga com as histórias de vida dos estudantes.

Ao explorar a organização dos TG, cabe-nos acentuar que a educação ambiental pautada nesses temas permeia todo o fazer pedagógico desenvolvido na escola, pois uma das bandeiras defendidas pela instituição é a construção de um ambiente socialmente justo e equilibrado. No Plano de Desenvolvimento Institucional (PDI) do CEIER-AB (2017), está descrito que a missão da instituição é a promoção de uma educação de excelência, que se esforça para formar cidadãos críticos, criativos, competentes e humanistas, numa intensa articulação entre ensino, pesquisa e interação com o meio socioambiental, contribuindo para o desenvolvimento sustentável da região. O objetivo geral da Unidade Escolar, segundo o PDI (2017, p. 7) é:

Promover a formação integral do ser humano, preparando-o para o exercício pleno da cidadania, a fim de criar melhorias nas condições de trabalho e dignidade para as famílias camponesas, propiciando assim uma sensibilização na preservação do meio ambiente através da proposta agroecológica, buscando a cooperação entre órgãos, entidades e comunidade.

Para que a formação integral dos estudantes aconteça, a escola, em seu PDI, estabelece vários objetivos específicos, dentre eles cabe-nos destacar:

Formar cidadãos críticos, criativos, competentes e humanistas; Promover a organização e valorização do camponês; Trabalhar o resgate histórico dos valores, das tradições culturais e dos costumes; Integrar Centro à 
Comunidade através de cursos, palestras e visitas; Desenvolver, planejar e avaliar atividades junto às comunidades; Criar tecnologias adaptáveis à agricultura familiar; Aplicar projetos pedagógicos; Utilizar a ética profissional e o desenvolvimento pessoal; Motivar a permanência dos estudantes na escola, evitando o índice de evasão; Buscar melhorias no desempenho dos estudantes nas avaliações internas e externas; Proporcionar ao estudante o domínio da leitura, da escrita e do raciocínio lógico; Possibilitar o acesso dos jovens moradores do campo ao Ensino Médio e Profissionalizante, sem ter a necessidade de se deslocar para os centros urbanos; Estabelecer metas para garantir a eficiência do Ensino Médio Integrado com o Curso Técnico em Agropecuária; Garantir a frequência e a permanência dos estudantes em Tempo Integral na Unidade de Ensino com dignidade. (PDI, 2017, p. 7-8).

O currículo da escola valoriza a formação integral e integradora dos estudantes. Contribui para o protagonismo dos sujeitos, individuais e coletivos, enaltecendo as tradições culturais, o trabalho coletivo, a ética e o comprometimento frente à realidade em que vivem e atuam. É nessa busca por uma educação emancipatória que o CEIER-AB desenvolve o seu fazer pedagógico, a partir dos desdobramentos dos TG. Numa busca constante pela integração dos conteúdos programáticos com a realidade de vida dos estudantes, o Centro busca ser um mediador dos espaços formativos, oportunizando aos estudantes, oficinas, estudos dirigidos, aulas de aprofundamento, trabalhos de campo, aprofundamento científico e produção de sínteses.

O CEIER-AB, no trabalho com os TG, utiliza o método "Ver, Julgar, Agir e Celebrar". Ver se refere à busca pelo conhecimento produzido pela sociedade, objetivando a libertação e a transformação da realidade camponesa. Julgar permeia as inúmeras reflexões sobre a sociedade emancipadora projetada pelos sujeitos, individuais e coletivos. Julga-se a realidade a partir de uma pedagogia libertadora. Agir é o momento de selecionar e programar, coletivamente, as diversas atividades assumidas por todos na escola. Celebrar é contemplar as tarefas realizadas, reconhecendo que a realidade é dinâmica e pode ser ressignificada.

\section{A sistematização do trabalho com os temas geradores no CEIER-AB}

A consulta ao acervo documental do CEIER-AB, o acompanhamento das reuniões de planejamento coletivo nas tardes de quarta-feira, as observações realizadas in loco, as inúmeras conversas com estudantes ${ }^{6}$ e professores da $3^{\text {a }}$ Série do Ensino Médio Integrado ao Curso Técnico em Agropecuária, além da análise das respostas dos questionários,

\footnotetext{
${ }^{6}$ Para manter o anonimato dos estudantes, escolhemos a sigla EC (Estudante do Campo) para identificá-los. Rev. Ed. Popular, Uberlândia, v. 19, n. 2, p. 240-257, maio-ago. 2020 
possibilitaram uma apreensão do fazer pedagógico da Instituição a partir dos TG. O trabalho com esses temas é organizado, sistematicamente, em etapas/atividades distintas que se entrelaçam.

Nesse processo de investigação das atividades realizadas com os TG, o primeiro questionamento feito aos estudantes foi: explique como acontece o trabalho com os Temas Geradores. As respostas dadas por eles nos ajudaram a entender o funcionamento da escola e a metodologia adotada. O EC 2 (2018) relata que "O Tema Gerador de cada trimestre tem um subtema voltado para o meio ambiente. Em cada trimestre nós visitamos propriedades diferentes e em algumas propriedades fazemos até reflorestamento". Já o EC 6 (2018) afirma que

A cada trimestre ocorre o trabalho com o Tema Gerador. Fazemos um levantamento das comunidades em que os estudantes residem e também apontamos os problemas gerados pelo ser humano e a solução para tais problemas. No aprofundamento científico, cada matéria aprofunda sobre as questões apontadas pelo tema.

As respostas dos estudantes indicam que o desenvolvimento do trabalho pedagógico, a partir dos TG, contribui para um fazer pedagógico, teórico-prático, voltado para a compreensão crítica e transformação da realidade e aportuniza que as questões ambientais sejam consideradas no transcorrer do processo de ensino e aprendizagem. O EC 6 reconhece que os professores e suas disciplinas dialogam com as problemáticas surgidas nos TG, por meio de aprofundamento teórico e científico, aliado aos diferentes saberes da educação popular, produzidos pelos estudantes. Silva (2011) reforça a importância de manter esse alinhamento entre os saberes, não sobrepondo um ao outro, dada a existência de uma diversidade epistemológica grandiosa que precisa ser visibilizada para compreensão e transformação da realidade. Nessa trajetória, o EC 11 detalha a forma como compreende o fazer pedagógico em torno dos TG:

São trabalhados os mesmos temas todos os anos. São eles: solo e questão agrária, água e agrofloresta. Depois são divididos os subtemas para cada turma. Feito isso, os estudantes escolhem as perguntas para a realização de uma pesquisa nas comunidades. Na sala de aula é debatido sobre as problemáticas identificadas nas entrevistas por comunidade. É elaborada uma divisão de conteúdos, por área do conhecimento. Os estudantes escolhem os conteúdos que querem estudar de acordo com o subtema e são cobradas atividades em cima disso. Pode haver diferença na forma que cada professor aborda esses temas.

Rev. Ed. Popular, Uberlândia, v. 19, n. 2, p. 240-257, maio-ago. 2020 
A fala do estudante EC 11 demonstra uma visão ampla de todo o fazer pedagógico em torno dos TG. Percebemos também um protagonismo estudantil muito forte, dado que os estudantes são sujeitos de todo processo. Além disso, compreendem a existência da interdisciplinaridade em torno dos temas. Essas questões são confirmadas na resposta do professor $^{7}$ PCA 1:

A maior marca do Tema Gerador é a interdisciplinaridade. Contamos com horas de planejamento exclusivas para essa atividade. Portanto, os Temas que são trabalhados durante o ano letivo são inseridos nas disciplinas e são ajustados para que aconteça um momento de prática, como um reflorestamento em propriedades adjacentes. Em resumo, esse trabalho alinha a prática à teoria e culmina com extensão.

Em seu discurso, o PCA 1 também chama a atenção para existência de um alinhamento entre teoria e prática, no percurso formativo que envolve o TG. Elas caminham juntas. Segundo Freire (2014), todo fazer dialoga, geralmente, com uma teoria. O que fazer é teoria e prática. É reflexão e ação. O tratamento dado à palavra não pode ser reduzido nem ao verbalismo nem ao ativismo. Nesse sentido, o PL 3 esclarece como o trabalho pedagógico com os temas é desenvolvido:

Os Temas Geradores são direcionados a partir de uma visita de estudos (geralmente no campo: propriedade agrícola, parque etc.) para posteriormente serem elaboradas questões acerca dos objetivos propostos. Após debate em sala, os próprios estudantes elaboram uma pesquisa da realidade que será levada para suas famílias responderem. A socialização dessa pesquisa é importante para o desenvolvimento de todas as atividades que ocorrerão durante o trimestre, sendo realizadas por área do conhecimento ou não, incluindo as atividades práticas.

As falas dos sujeitos e o acervo documental da escola, aliados às constantes vivências e observações, foram fundamentais para sistematizarmos o trabalho que a escola desenvolve a partir dos TG. Nessa abordagem investigativa, que tece todo o fazer pedagógico, conseguimos agrupar de forma geral e com o intuito de facilitar a compreensão do processo, doze momentos que compõem o trabalho com os TG durante os trimestres no CEIER-AB.

$1^{0}$ momento: Planejamento dos professores. A etapa inicial de desenvolvimento do trabalho pedagógico a partir dos TG consiste no planejamento dos docentes para iniciar a apresentação do tema para os estudantes. Nessa fase, os professores utilizam o momento da reunião de planejamento coletivo, na quarta-feira à tarde, para traçar as estratégias de

\footnotetext{
${ }^{7}$ Para manter o anonimato dos professores, escolhemos as seguintes siglas, de acordo com a área de conhecimento que atuam: PCA (Professor de Ciências Agrárias); PL (Professor de Linguagens); PCHS (Professor de Ciências Humanas e Sociais); e PCNM (Professor de Ciências da Natureza e Matemática). 
implementação dos TG e definir os professores que acompanharão cada turma durante o ano letivo.

$2^{\circ}$ momento: Abertura do TG. Nessa fase, todo o corpo docente e discente se reúne num galpão para apreciação e execução da grande mística. São apresentados vários elementos simbólicos, como por exemplo, enxadas com a ponta de um lápis, bandeiras, livros, vídeos, músicas, entre outros aspectos, que representam os instrumentos pedagógicos da educação do campo. A mística tem a intenção de apresentar no coletivo o TG do trimestre, em diálogo com as atividades da escola.

$3^{\mathbf{0}}$ momento: Motivação dos estudantes para pesquisa da realidade. Cada professor acompanhante de turma é responsável por organizar e executar essa etapa junto a sua turma. Trata-se de um momento processual composto por várias atividades, tais como ornamentação da sala de aula, de acordo com as temáticas; místicas para apresentação dos subtemas; apreciação de vídeos e músicas; visitas de estudos e permanente diálogo motivador e reflexivo.

Nesse período de motivação são apresentados os subtemas, de modo que os estudantes compreendam e opinem sobre o que estudar, para que, como, por que, quando, onde e os possíveis desdobramentos dos TG. Espera-se que os estudantes criem hipóteses e, a partir delas, elaborem questionamentos, problemáticas e perguntas. Tais questões são analisadas coletivamente pelos professores acompanhantes das turmas, considerando sua relevância e pertinência em relação ao subtema de estudo, além da necessidade de construção e implementação do roteiro de pesquisa e observação.

$4^{0}$ momento: Realização da pesquisa junto à família/comunidade. A partir de um roteiro estruturado com pontos de observação e perguntas, os estudantes realizam uma pesquisa participativa junto à família e/ou comunidade. Essa pesquisa e as demais partes do trabalho com o TG são registradas no Caderno da Realidade. Nesse instrumento pedagógico, os estudantes registram suas percepções e reflexões acerca da realidade estudada.

$5^{\circ}$ momento: Colocação em comum da pesquisa sobre a realidade. Na colocação em comum, os estudantes agrupados, geralmente, por comunidades, apresentam uma síntese individual da pesquisa de campo realizada na comunidade. Essa síntese não é a resposta isolada de perguntas e registros de observações. Ela é sistematizada em forma de texto, colaborando na compreensão da realidade, no processo de escrita e desenvolvimento dos estudantes. A partir das problematizações resultantes das sínteses apresentadas na sala de aula, os professores acompanhantes de turma elaboram, junto aos estudantes, um esquema 
denominado "Teia do Conhecimento". Nessa teia, os pontos de aprofundamentos e as problemáticas emergentes são distribuídos, de forma didática, entre as diferentes áreas do conhecimento.

$6^{\circ}$ momento: Reunião coletiva de aprofundamento científico. Durante o planejamento coletivo, os professores acompanhantes das turmas apresentam as atividades e os trabalhos, em comum, desenvolvidos junto aos estudantes. Fazem a apreciação e análise da pertinência das diferentes Teias do Conhecimento elaboradas pelas turmas, bem como a organização dos conteúdos por área de conhecimento.

$7^{\circ}$ momento: Aprofundamento científico por área de conhecimento. Essa atividade acontece durante o planejamento coletivo. Os professores se reúnem com os demais pares de suas respectivas áreas do conhecimento: Linguagens; Ciências Humanas e Sociais; Ciências da Natureza, Matemática e Ciências Agrárias, para planejar estratégias de desenvolvimento do trabalho com os TG. Nessa etapa, os professores identificam os anseios contemplados, os conteúdos a serem trabalhados e organizam atividades integradoras com o intuito de abranger cada área de conhecimento.

$8^{\circ}$ momento: Execução do planejamento por área. Os conteúdos científicos que se desdobram dos TG estão presentes nas aulas de aprofundamento científico, teórico e prático. Nessa etapa, geralmente os professores acompanhantes das turmas organizam palestras e aulas práticas. Importante sinalizar, nessa conjuntura, que as disciplinas da Base Nacional Curricular Comum (BNCC) são trabalhadas de forma articulada com os conteúdos vinculados aos TG e o Currículo Básico da Rede Estadual do Espírito Santo, estabelecendo um esforço considerável de diálogo entre ambos.

$9^{\circ}$ momento: Transformação da realidade. Nesse momento, os estudantes realizam atividades práticas no intuito de intervir na realidade estudada. Cada turma realiza ações concretas de intervenção, como, por exemplo, plantio de mudas em áreas degradadas, reflorestamento das nascentes, entre outras ações de ordem prática. Todas as ações executadas pelas turmas são sistematizadas na forma de síntese e/ou relatos que serão inseridos no Caderno da Realidade.

$10^{\circ}$ momento: Celebração dos trabalhos realizados. As turmas, acompanhadas dos professores, reúnem-se no galpão da escola para celebrar o aprendizado construído a partir dos trabalhos com os TG. Nessa celebração, os estudantes fazem apresentações artísticas e difundem as atividades práticas realizadas. Cada turma tem o seu momento de apresentação e partilha coletiva dos saberes da educação popular e científica produzidos. 
$11^{\circ}$ momento: Entrega do Caderno da Realidade. Nessa penúltima etapa, os estudantes entregam os Cadernos da Realidade aos professores acompanhantes de turma para apreciação e avaliação. A partir desses cadernos é possível ter uma visão geral de grande parte do processo que envolve o trabalho com os TG. Nessa etapa, os professores avaliam não só o caderno, mas todo o desenrolar pedagógico durante o trimestre. Essa avaliação, em termos quantitativos, corresponde à terça parte da nota do trimestre.

O Caderno da Realidade é muito comum nas escolas de Educação do Campo. Acerca desse instrumento pedagógico, Silva (2011, p. 70) expõe que "é um gênero que possibilita sistematizar e organizar os conhecimentos escolares em seus textos segundo a realidade das práticas educativas empreendidas". Dialogando com esse pensamento, acrescenta que os "registros escritos exigem dos jovens tanto leitura quanto reflexão a respeito da língua para produção dos diferentes gêneros discursivos que são específicos do contexto educativo" (SILVA, 2018, p. 210). Dentro dessa complexidade que envolve esse instrumento pedagógico, Caliari (2013, p. 425) expõe que o Caderno da Realidade

é o documento em que o jovem registra suas impressões e reflexões dos estudos e aprofundamentos realizados na escola. É a sistematização das reflexões e ações geradas na escola, na família e comunidade camponesa. É o lugar onde ficam ordenadas todas as reflexões sobre as experiências motivadas na escola que possibilitaram ligar o saber ao fazer dentro da realidade dos educandos e, principalmente, onde se manifesta a cooperação da família para a realização das tarefas propostas na estada familiar, uma vez que estimula o diálogo entre os membros da família, pais e filhos, despertando a compreensão mútua sobre os temas tratados.

As observações durante os momentos de trabalho com o Caderno da Realidade também nos possibilitam enxergar esse instrumento como um suporte para registro das experiências educativas que envolvem o TG e utilizam a realidade como ponto de partida para problematização e posterior estudo científico de temas que emergem do meio social dos sujeitos: estudantes do campo.

$12^{\circ}$ momento: Avaliação dos trabalhos realizados. Essa avaliação ocorre entre os acompanhantes de turma, estudantes, professores e seus pares. Ela permite elencar propostas de aperfeiçoamento do método de trabalho, quando necessário. Cabe-nos abordar que a avaliação, sobretudo, a autoavaliação, é realizada durante todo o processo e permeia cada etapa de formação. Nesse sentido, é possível estabelecer mudanças e incentivar a correção de rotas. 


\section{Considerações finais}

O CEIER-AB oportuniza aos estudantes amplo conhecimento da realidade em que vivem, propondo, durante todo trabalho com os TG, a estreita relação entre teoria e prática, ação e reflexão. A lógica de funcionamento metodológico da escola aponta que o trabalho pedagógico busca uma constante articulação entre os saberes científicos e populares, estabelecendo, entre ambos, possíveis interconexões, sem sobreposição. $O$ trabalho apresentado pelo CEIER-AB contribui para os estudantes potencializarem o sentimento de pertença e valorização dos sonhos, gestos, desejos, memórias e identidades, desenvolvendo o pensamento crítico e emancipador, protagonizado nas suas histórias de vida.

O trabalho desenvolvido a partir dos TG tem bastante proximidade com as teorias defendidas por Freire (2014), no livro Pedagogia do Oprimido, dado que o autor não propunha métodos prontos e acabados, mas sim ideias para que cada instituição pensasse formas de trabalho a partir delas. Diante disso, compreendemos que o CEIER-AB, ao utilizar a nomenclatura tema gerador, na interface com o fortalecimento da palavra, apresenta uma visão particular, mas não única, da relação dos TG com o trabalho pedagógico.

Nessa direção, a instituição considera a realidade das comunidades, dos estudantes, no diálogo com o currículo oficial. O CEIER-AB se esforça na aproximação entre os conteúdos do Currículo Básico das Escolas da Rede Estadual do Espírito Santo e a realidade dos estudantes. Muito embora a escola não construa todo conteúdo programático, como sugere Freire (2014), há constante integração entre os pontos de aprofundamento dos TG e o currículo oficial.

\section{Referências}

BICALHO, R.; OLIVEIRA, J. R. Interfaces entre educação profissional e pedagogia da alternância. Série-Estudos (UCDB), Campo Grande, v. 22, n. 46, p. 195-212, set./dez, 2017. Doi: $10.20435 /$ serie-estudos.v22i46.967.

BICALHO, R. História da educação do campo no Brasil: o protagonismo dos movimentos sociais. Teias, Rio de Janeiro, v. 18, n. 51, p. 210-224, out./dez. 2017. Doi: 10.12957/teias.2017.24758.

BICALHO, R; SILVA, M. A. Políticas públicas em educação do campo: Pronera, Procampo e Pronacampo. Revista Eletrônica de Educação, São Carlos, v. 10, n. 2, p. 135-144, 2016. Doi: $10.14244 / 198271991549$. 
CALIARI, R. A presença da família camponesa na escola família agrícola: o caso de Olivânia. 2013. 563f. Tese (Doutorado em Educação) - Universidade Federal do Espírito Santo, Vitória, 2013.

FREIRE, P. Pedagogia do oprimido. 57. ed. rev. e atual. Rio de Janeiro: Paz e Terra, 2014.

GIL, A. C. Métodos e técnicas de pesquisa social. 6. ed. São Paulo: Atlas, 2008.

PDI - Plano de Desenvolvimento Institucional. Centro Estadual Integrado de Educação Rural de Águia Branca. 2017.

SILVA, C. Pedagogia da alternância: um estudo do gênero caderno da realidade com foco na retextualização. 2011. 149f. Dissertação (Mestrado em Letras) - Universidade Federal do Tocantins, Araguaína, 2011.

SILVA, C. Pedagogia da alternância: práticas de letramentos em uma Escola Família Agrícola brasileira. 2018. 232f. Tese (Doutorado em Letras) - Universidade Federal do Tocantins, Araguaína, 2018.

Submetido em 7 de janeiro de 2020.

Aprovado em 17 de março de 2020. 